\title{
GIÁ TR! CỦA CỌNG HƯỞNG TỪ 3 TESLA TRONG CHẨN ĐOÁN TỎN THƯƠNG ĐÁM RÓI THẦN KINH CÁNH TAY Ở TRẺ EM DO CHẤN THƯO'NG SẢN KHOA
} Ngô Văn Đoan ${ }^{1}$, Bùi Văn Giang ${ }^{2}$, Nguyễn Hồng Hà ${ }^{3}$ và Vương Kim Ngân ${ }^{1, 凶}$

${ }^{1}$ Hệ thống Y tế Vinmec, Hà Nội, Việt Nam

${ }^{2}$ Bệnh Viện K

${ }^{3}$ Bệnh viện Hữu nghị Việt Đức

Đánh giá giá trị của cộng hưởng từ (CHT) 3Tesla (3T) trong chẩn đoán tổn thương đám rối thần kinh cánh tay (ĐRTKCT) sản khoa. Phương pháp nghiên cứu tiến cứu trên 47 bệnh nhân có triệu chứng lâm sàng và điện cơ của tổn thương đám rối thần kinh cánh tay sản khoa. Toàn bộ bệnh nhân được chụp CHT 3TĐRTKCT trước phẫu thuật tại BV đa khoa quốc tế Vinmec (Hà Nội, Việt Nam) từ 09/2016 đến 03/2020 và điều trị phẫu thuật tại BV Việt Đức và BV Nhi trung ương (Hà Nội, Việt Nam). Các tổn thương trước hạch và sau hạch được mô tả và đối chiếu với kết quả phẫu thuật. Độ nhạy, độ đặc hiệu, độ chính xác, giá trị dụ đoán dương tính và giá trị dụ̂ đoán âm tính đối với chẩn đoán tổn thương trước hạch lần lượt là $89,7 \%, 93,2 \%, 92,3 \%, 81,3 \%$ và $96,5 \%$; đối với chẩn đoán tổn thương đứt rễ thần kinh sau hạch lần lượt là $78,7 \%, 89,8 \%, 84,7 \%, 86,7 \%$ và $83,2 \%$; và đối với chẩn đoán neuroma rễ thần kinh lần lượt là 92,6\%, 84,3\%,87,2\%,75,6\% và 95,6\%. CHT 3T là phương pháp chẩn đoán không xâm nhập, có giá trị cao trong chẩn đoán tổn thương ĐRTKCT sản khoa ở trẻ em đối với cả tổn thương trước và sau hạch.

Từ khóa: tổn thương đám rối thần kinh sản khoa, cộng hưởng từ 3Tesla, liệt Erb.

\section{I. ĐẠT VẤN ĐÈ}

Tổn thương ĐRTKCT là loại tổn thương thần kinh ngoại biên, hầu hết xảy ra vùng trên xương đòn và các rễ thần kinh và thân hay bị tổn thương hơn là các bó, ngành và các nhánh tận. Tổn thương ĐRTKCT ở trẻ sơ sinh chiếm khoảng 0,5 - 3,0 trong số 1000 trẻ sinh sống mỗi năm, tổn thương có thể ảnh hưởng một hoặc một số rễ thần kinh từ $\mathrm{C} 5$ đến $\mathrm{T} 1$, trong đó rễ $\mathrm{C} 5$, $\mathrm{C} 6$ và $\mathrm{C} 7$ là các rễ thần kinh hay bị tổn thương nhất; rễ C8 và T1 thì ít gặp tổn thương hơn. ${ }^{1}$ Cơ chế chính của tổn thương ĐRTKCT là do cơ chế kéo căng ĐRTKCT trong quá trình chuyển dạ, có liên quan đến một số yếu tổ như cân nặng của thai nhi, kẹt ngôi vai, đái tháo đường, thời

Tác giả liên hệ: Vương Kim Ngân

Hệ thống Y tế Vinmec, Hà Nội, Việt Nam

Email: drkimngan.rad@gmail.com

Ngày nhận: 08/09/2021

Ngày được chấp nhận: 29/09/2021 gian chuyển dạ và các phương pháp hỗ trợ khi sinh qua đường âm đạo. ${ }^{1,2}$ Trước đây chẩn đoán tổn thương ĐRTKCT dựa trên lâm sàng và điện cơ, tuy nhiên đặc điểm lâm sàng đôi khi không đặc hiệu và ngay cả khi phối hợp với điện cơ cũng khó khăn trong việc xác định chính xác vị trí tổn thương trước hạch hay sau hạch - có ý nghĩa trong quyết định lựa chọn phương pháp và cách thức phẫu thuật. $\mathrm{CHT}$ đóng một vai trò quan trọng và cần thiết trong việc đánh giá chính xác vị trí tổn thương cũng như là mức độ tổn thương. ${ }^{3}$ Tại Việt Nam, từ khi có máy chụp $\mathrm{CHT}$ 3T với độ phân giải cao, chẩn đoán tổn thương ĐRTKCT sản khoa ở trẻ em trở nên chính xác hơn trong việc phát hiện loại tổn thương, vị trí, mức độ tổn thương và tổn thương tủy cổ phối hợp nếu có, từ đó nhằm đưa ra kế hoạch điều trị thích hợp nhất và tiên lượng giúp bệnh nhân được phẫu thuật đúng thời điểm và phục hồi tối đa tổn thương thần kinh, tránh để lại di chứng 
nặng nề. Tuy nhiên, các nghiên cứu về vai trò của CHT 3T trong đánh giá tổn thương ĐRTKCT sản khoa ở trẻ em trong nước còn chưa nhiều. Vì vậy xuất phát từ thực tế lâm sàng, chúng tôi tiến hành nghiên cứu với mục đích đánh giá giá trị của $\mathrm{CHT} 3 \mathrm{~T}$ trong đánh giá tổn thương ĐRTKCT sản khoa ở trẻ em.

\section{II. ĐỐI TƯỢNG VÀ PHƯO'NG PHÁP}

\section{1. Đối tượng}

47 bệnh nhân có triệu chứng lâm sàng của tổn thương ĐRTKCT sau sinh có liên quan tới chấn thương sản khoa, có kết quả điện cơ của tổn thương ĐRTKCT sản khoa, được chụp CHT 3T ĐRTKCT trước phẫu thuật tại BV đa khoa quốc tế Vinmec (Hà Nội, Việt Nam) từ tháng 09 năm 2016 đến tháng 03 năm 2020; sau đó được điều trị phẫu thuật tại BV Việt Đức, BV Nhi trung ương (Hà Nội, Việt Nam) để đối chiếu và có hồ sơ bệnh án ghi chép đầy đủ.

\section{Phương pháp}

Nghiên cứu mô tả tiến cứu.

Kỹ thuật chụp CHT ĐRTKCT được thống nhất theo quy trình tại bệnh viện đa khoa quốc tế Vinmec (Hà Nội, Việt Nam).

Kỹ thuật được tiến hành trên máy $\mathrm{CHT}$ 3T (MAGNETOM Skyra, Siemens Healthcare) với các chuỗi xung Coronal 2D - T1W (FOV 300 $\mathrm{mm}$, độ dày lát cắt $4 \mathrm{~mm}$, TR/TE 880/11, ma trận 512 x 512), Coronal 3D - STIR (FOV 300 $\mathrm{mm}$, độ dày lát cắt $0,5-1 \mathrm{~mm}, \mathrm{TR} / \mathrm{TE} 3000 / 198$, ma trận 320 x 384), Sagittal 2D - T2W (FOV $300 \mathrm{~mm}$, độ dày lát cắt $3 \mathrm{~mm}, \mathrm{TR} / \mathrm{TE} 3700 / 85$, ma trận 320 x 384), Coronal CISS (FOV 200 $\mathrm{mm}$, độ dày lát cắt $2 \mathrm{~mm}, \mathrm{TR} / \mathrm{TE} 8,5 / 4$, ma trận 320 x 384) và Axial CISS (FOV 300 mm, độ dày lát cắt 2,5 mm, TR/TE 9/4, ma trận 320 x 384).

Quy trình và phương pháp thu thập số liệu

Toàn bộ phim chụp được đọc bởi một bác sĩ chẩn đoán hình ảnh làm nghiên cứu trên hệ thống PACS lưu trữ của hệ thống GE Healthcare để đảm bảo tính đồng nhất của kết quả.

Đánh giá mức độ nặng của tổn thương rễ thần kinh trên hình ảnh $\mathrm{CHT}$ dựa theo phân độ Sunderland.

Phân loại vị trí tổn thương theo tương quan với hạch thần kinh tủy sống gồm tổn thương trước hạch, sau hạch hoặc cả hai. Đánh giá và thống kê các tổn thương trên hình ảnh $\mathrm{CHT}$ bao gồm tổn thương trước hạch, tổn thương sau hạch hoặc cả hai. Tổn thương trước hạch bao gồm: nhổ rễ con là sự mất liên kết của rễ thần kinh đối với cột tủy, có thể kèm theo giả thoát vị màng não tủy hoặc không; giả thoát vị màng não tủy là sự thoát dịch não tủy do vết rách của màng cứng, giả thoát vị màng não tủy có thể nằm trong ống sống hoặc lan theo rễ thần kinh; tổn thương bất thường tủy cổ như phù tủy, nhuyễn tủy, rỗng tủy (tăng tín hiệu T2W) tới ứ sắt khu trú do giáng hóa của máu (giảm tín hiệu T2W), tổn thương thường có xu hướng lan rộng và liên quan tới phần rễ bị tổn thương, ngoài ra cột tủy cổ có thể bị di lệch. ${ }^{4}$ Tổn thương sau hạch bao gồm đứt rời rễ sau hạch là sự mất liên tục của rễ thần kinh, ngoài ra có thể biểu hiện một số dấu hiệu gián tiếp như tụ dịch quanh vị trí đứt rách thần kinh (tăng tín hiệu T2W); dày khu trú dây thần kinh gợi ý quá trình xơ hóa quanh vị trí đứt ở giai đoạn mạn tính và teo các cơ trên gai, dưới gai (có dấu hiệu phù và tăng tín hiệu ở giai đoạn cấp và teo cơ xuất hiện sau đó; u xơ thần kinh là sự dày lên khu trú của dây thần kinh tạo thành khối hình bầu dục giới hạn rõ liên tiếp với dây thần kinh với tín hiệu cao trên ảnh T2W. Ngoài ra có thể thấy dấu hiệu khác của tổn thương sau hạch như phù nề tăng tín hiệu lan tỏa rễ thần kinh trên ảnh $T 2 W$ và xơ hóa phần mềm quanh rễ thần kinh với tín hiệu giảm trên ảnh T2W và co kéo cấu trúc dây thần kinh lân cận. ${ }^{4}$

\section{Xử lí và phân tích số liệu}

Các số liệu được thu thập theo mẫu bệnh án nghiên cứu, nhập số liệu bằng phần mềm 
Epi - Info, thống kê và xử lý số liệu bằng phần mềm SPSS 20.0 (SPSS, IBM, NY, USA). Giá trị của các các hình thái tổn thương tổn thương ĐRTKCT ở trước hạch và sau hạch trên $\mathrm{CHT}$ được tính toán và so sánh với tổn thương ĐRTKCT sau phẫu thuật để đưa ra các giá trị độ nhạy (Se), độ đặc hiệu (Sp), giá trị dự đoán dương tính (PPV), giá trị dự đoán âm tính (NPV) và độ chính xác (ACC).

\section{4. Đạo đức nghiên cứu}

Bài báo này là một phần kết quả thuộc đề tài Nghiên cứu đặc điểm hình ảnh và giá trị của $\mathrm{CHT} 3 \mathrm{~T}$ trong chẩn đoán tổn thương đám rối thần kinh cánh tay ở trẻ em do chấn thương sản khoa» đã được Hội đồng Đạo đức trong nghiên cứu Y sinh học Đại học Y Hà Nội (IRB00003121) thông qua ngày 06 tháng 01 năm 2017, theo quyết định số 22/HĐĐĐĐHYHN. Các bệnh nhân trong nghiên cứu được chỉ định chụp $\mathrm{CHT}$ $3 T$ đám rối thần kinh cánh tay nhằm mục đích đánh giá mức độ tổn thương để phục vụ điều trị vì lợi ích của người bệnh. Bệnh nhân/người giám hộ bệnh nhân được giải thích kỹ càng về mục đích của nghiên cứu, đồng ý và ký cam kết tham gia nghiên cứu.

\section{KÉT QUẢ}

\section{1. Đặc điểm chung}

Trong 47 bệnh nhân của nghiên cứu có 29 bệnh nhân nữ (chiếm 61,7\%) và 18 bệnh nhân

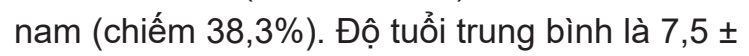
17,87 (tháng), trong đó trẻ nhỏ nhất là 1 tháng tuổi và lớn nhất là 108 tháng tuổi. Cân nặng trung bình là $3917 \pm 559,24$ (gram), trong đó cân nặng nhỏ nhất là 1400 gam và lớn nhất là 4700 gam. Bên tay bị tổn thương chiếm đa số là bên phải (chiếm 70,21\%) và tổn thương theo phân độ Nakaras trên lâm sàng chủ yếu là độ 3 và 4 chiếm lần lượt là $38,30 \%$ và $34,04 \%$, tổn thương theo phân độ Nakaras 1 và 2 lần lượt là $4,26 \%$ và $23,40 \%$.

\section{Giá trị của $\mathrm{CHT}$ trong đánh giá tổn thương đám rối thần kinh cánh tay}

Mức độ tổn thương các rễ thần kinh trên $\mathrm{CHT}$ theo phân loại Sunderland được trình bày ở bảng 1 .

Bảng 1. Mức độ tổn thương theo Sunderland các rễ thần kinh trên phim chụp $\mathrm{CHT}$

\begin{tabular}{lccccc}
\hline & Bình thường & Độ I & Độ II - III & Độ IV & Độ V \\
\hline C5 $(n=47)$ & $0 \%$ & $0 \%$ & $19,1 \%$ & $25,5 \%$ & $55,3 \%$ \\
\hline C6 $(n=47)$ & $0 \%$ & $0 \%$ & $19,1 \%$ & $27,7 \%$ & $53,2 \%$ \\
\hline C7 $(n=47)$ & $6,4 \%$ & $0 \%$ & $19,1 \%$ & $6,4 \%$ & $68,1 \%$ \\
\hline C8 $(n=47)$ & $29,8 \%$ & $4,3 \%$ & $4,3 \%$ & $6,4 \%$ & $55,3 \%$ \\
\hline T1 $(n=47)$ & $51,1 \%$ & $8,5 \%$ & $4,3 \%$ & $2,1 \%$ & $34,0 \%$ \\
\hline Chung $(n=235)$ & $17,4 \%$ & $2,6 \%$ & $13,2 \%$ & $13,6 \%$ & $53,2 \%$ \\
\hline
\end{tabular}

Rễ thần kinh $\mathrm{C} 5, \mathrm{C} 6$ và $\mathrm{C} 7$ là các rễ thần kinh hay gặp tổn thương, trong đó tổn thương độ $\mathrm{V}$ chiếm tỷ lệ cao nhất $55,3 \%, 53,2 \%$ và $68,1 \%$. Các rễ $\mathrm{C} 8$ và $\mathrm{T} 1$ có tổn thương mức độ $\mathrm{V}$ là hay gặp nhất, chiếm $55,3 \%$ và $34,0 \%$.

Bảng 2. Giá trị của CHT $3 \mathrm{~T}$ trong phát hiện tổn thương nhổ rễ

\begin{tabular}{lccccc}
\hline & Se & Sp & PPV & NPV & ACC \\
\hline C5 $(n=47)$ & $75 \%$ & $97,7 \%$ & $75 \%$ & $97,7 \%$ & $95,7 \%$ \\
\hline C6 $(n=47)$ & $83,3 \%$ & $95,1 \%$ & $71,4 \%$ & $97,5 \%$ & $93,6 \%$ \\
\hline
\end{tabular}




\begin{tabular}{lccccc}
\hline & Se & Sp & PPV & NPV & ACC \\
\hline C7 $(n=47)$ & $100 \%$ & $93,3 \%$ & $89,5 \%$ & $100 \%$ & $95,7 \%$ \\
\hline C8 $(n=47)$ & $94,1 \%$ & $80 \%$ & $72,7 \%$ & $96 \%$ & $85,1 \%$ \\
\hline T1 $(n=47)$ & $90,9 \%$ & $91,7 \%$ & $76,9 \%$ & $97,1 \%$ & $91,5 \%$ \\
\hline Chung $(n=235)$ & $92,7 \%$ & $92,2 \%$ & $78,5 \%$ & $97,7 \%$ & $92,3 \%$
\end{tabular}

Độ nhạy, độ đặc hiệu, độ chính xác, giá trị dự đoán dương tính và giá trị dự đoán âm tính đối với chẩn đoán tổn thương nhổ rễ lần lượt là 92,7\%,92,2\%, 92,3\%, 78,5\% và 97,7\%.

Bảng 3. Giá trị của CHT 3 T trong phát hiện tổn thương trước hạch

\begin{tabular}{lccccc}
\hline & Se & Sp & PPV & NPV & ACC \\
\hline C5 $(n=47)$ & $60 \%$ & $100 \%$ & $100 \%$ & $95,5 \%$ & $95,7 \%$ \\
\hline C6 $(n=47)$ & $71,4 \%$ & $100 \%$ & $100 \%$ & $95,3 \%$ & $95,7 \%$ \\
\hline C7 $(n=47)$ & $100 \%$ & $93,3 \%$ & $89,5 \%$ & $100 \%$ & $95,7 \%$ \\
\hline C8 $(n=47)$ & $94,4 \%$ & $79,3 \%$ & $73,9 \%$ & $95,8 \%$ & $85,3 \%$ \\
\hline T1 $(n=47)$ & $90,9 \%$ & $88,9 \%$ & $71,4 \%$ & $96,9 \%$ & $89,4 \%$ \\
\hline Chung $(n=235)$ & $89,7 \%$ & $93,2 \%$ & $81,3 \%$ & $96,5 \%$ & $92,3 \%$ \\
\hline
\end{tabular}

Độ nhạy, độ đặc hiệu, độ chính xác, giá trị dự đoán dương tính và giá trị dự đoán âm tính đối với chẩn đoán tổn thương trước hạch lần lượt là 89,7\%,93,2\%, 92,3\%, 81,3\% và 96,5\%.

Bảng 4. Giá trị của CHT 3 T trong phát hiện tổn thương đứt rễ sau hạch

\begin{tabular}{lccccc}
\hline & Se & Sp & PPV & NPV & ACC \\
\hline C5 $(n=47)$ & $89,2 \%$ & $70 \%$ & $91,7 \%$ & $63,6 \%$ & $85,1 \%$ \\
\hline C6 $(n=47)$ & $81,8 \%$ & $64,3 \%$ & $84,4 \%$ & $60 \%$ & $76,6 \%$ \\
\hline C7 $(n=47)$ & $72 \%$ & $90,9 \%$ & $90 \%$ & $74,1 \%$ & $80,9 \%$ \\
\hline C8 $(n=47)$ & $57,1 \%$ & $95 \%$ & $66,7 \%$ & $92,7 \%$ & $89,4 \%$ \\
\hline T1 $(n=47)$ & $50 \%$ & $97,6 \%$ & $75 \%$ & $93 \%$ & $91,5 \%$ \\
\hline Chung $(n=235)$ & $78,7 \%$ & $89,8 \%$ & $86,7 \%$ & $83,2 \%$ & $84,7 \%$ \\
\hline
\end{tabular}

Độ nhạy, độ đặc hiệu, độ chính xác, giá trị dự đoán dương tính và giá trị dự đoán âm tính đối với chẩn đoán tổn thương đứt rễ thần kinh sau hạch lần lượt là 78,7\%, 89,8\%, 84,7\%, 86,7\% và 83,2\%.

Bảng 5. Giá trị của CHT 3T trong phát hiện tổn thương u thần kinh (neuroma)

\begin{tabular}{lccccc}
\hline & Se & Sp & PPV & NPV & ACC \\
\hline C5 $(n=47)$ & $90,5 \%$ & $80,8 \%$ & $79,2 \%$ & $91,3 \%$ & $85,1 \%$ \\
\hline C6 $(n=47)$ & $91,7 \%$ & $78,3 \%$ & $81,5 \%$ & $90 \%$ & $85,1 \%$ \\
\hline C7 $(n=47)$ & $94,7 \%$ & $85,7 \%$ & $81,8 \%$ & $96 \%$ & $89,4 \%$ \\
\hline C8 $(n=47)$ & $90,9 \%$ & $83,3 \%$ & $62,5 \%$ & $96,8 \%$ & $85,1 \%$ \\
\hline
\end{tabular}




\begin{tabular}{lccccc}
\hline & Se & Sp & PPV & NPV & ACC \\
\hline T1 $(n=47)$ & $100 \%$ & $90 \%$ & $60 \%$ & $100 \%$ & $91,3 \%$ \\
\hline Chung $(n=235)$ & $92,6 \%$ & $84,3 \%$ & $75,6 \%$ & $95,6 \%$ & $87,2 \%$ \\
\hline
\end{tabular}

Độ nhạy, độ đặc hiệu, độ chính xác, giá trị dự đoán dương tính và giá trị dụ̣ đoán âm tính đối với chẩn đoán u thần kinh lần lượt là 92,6\%, 84,3\%, 87,2\%, 75,6\% và 95,6\%.

\section{BÀN LUÂNN}

Ứng dụng $\mathrm{CHT}$ đóng vai trò quan trọng trong chẩn đoán tổn thương ĐRTKCT sản khoa, góp phần cải thiện được tiên lượng và kết quả điều trị phẫu thuật so với thăm khám lâm sàng và điện cơ đơn thuần trước đây và giảm khả năng nhiễm xạ so với thăm khám bằng cắt lớp vi tính hay chụp tủy sống. CHT 3T có từ lực, độ phân giải cao so với $1,5 \mathrm{~T}$, giảm thời gian chụp và nhiễu ảnh do đó phù hợp với đối tượng trẻ em. ${ }^{5}$

Trong nghiên cứu của chúng tôi, tổn thương rễ $\mathrm{C} 5, \mathrm{C} 6$ và $\mathrm{C} 7$ là vị trí tổn thương hay gặp nhất, tương tư với nghiên cứu trước đó của tác giả Gunes và cộng sự năm 2018. ${ }^{6}$ Tổn thương nhổ rễ là một hình thái của tổn thương trước hạch, là sự mất liên tục hoặc không quan sát thấy rễ thần kinh liên tiếp với cột tủy, có thể nhổ rễ trước, rễ sau hoặc cả rễ trước và rễ sau. ${ }^{7}$ CHT 3T trong đánh giá nhổ rễ trong nghiên cứu của chúng tôi có giá trị cao với độ nhạy, độ đặc hiệu, độ chính xác, giá trị chẩn đoán dương tính và âm tính lần lượt là 92,7\%, 92,2\%, 92,3\%, $78,5 \%$ và $97,7 \%$. Tổn thương nhổ rễ có thể đi kèm với giả thoát vị màng não tủy hoặc không. Dấu hiệu giả thoát vị màng não tủy là sự hình thành túi chứa dịch não tủy do rách màng cứng có thể nằm ở trong ống sống hoặc theo đường đi của rễ thần kinh, là một dấu hiệu có tính đặc hiệu cao trong gợi ý tổn thương nhổ rễ. Theo Medina và cộng sự, độ nhạy và độ đặc hiệu của giả thoát vị màng cứng trong đánh giá nhổ rễ lần lượt là $50 \%$ và $100 \%$. Trong đánh giá tổn thương trước hạch nói chung, độ nhạy, độ đặc hiệu, độ chính xác, giá trị dự đoán dương tính và giá trị dự đoán âm tính trong nghiên cứu của chúng tôi lần lượt là $89,7 \%, 93,2 \%, 92,3 \%$, $81,3 \%$ và $96,5 \%$. Kết quả này cũng tương tự với các nghiên cứu trước đó của Gunes độ nhạy, độ đặc hiệu, độ chính xác, giá trị dụ̣ đoán dương tính và giá trị dụ̣ đoán âm tính lần lượt là $84 \%$, $96 \%, 92 \%, 92 \%$ và $92 \%$ và của Lihong Zhang ${ }^{7}$, độ nhạy, độ đặc hiệu và độ chính xác lần lượt là $93,55 \%, 71,43 \%$ và 89,47\%. Độ nhạy và độ chính xác trong chẩn đoán tổn thương trước hạch thấp hơn so với tổn thương nhổ rễ do ngoài tổn thương nhổ rễ, tổn thương trước hạch còn gồm một số tổn thương khác tại tủy sống mà trong đó một số ca có tổn thương di lệch cột tủy không được phát hiện trước phẫu thuật. Theo kinh nghiệm của chúng tôi, chuỗi xung Coronal CISS và Axial CISS được sử dụng để đánh giá các rễ con nối với cột tủy, ổ giả thoát vị màng não tủy, tổn thương tủy nếu có. Trong trường hợp không có bệnh lý, tín hiệu của các dây thần kinh, lớp mỡ xung quanh cũng như các cơ sẽ đồng nhất và phối hợp với chuỗi xung Coronal $3 \mathrm{D}$ - STIR để so sánh 2 bên cho phép đánh giá bên tổn thương. 

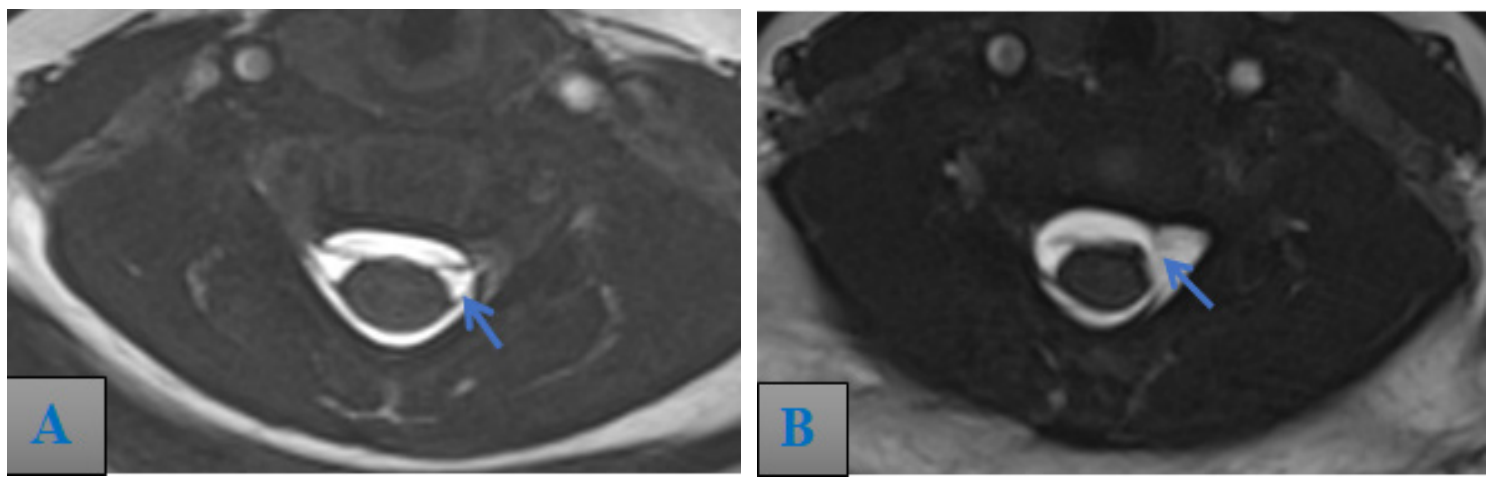

Hình 1. Axial CISS của bệnh nhân nữ 2 tháng tuổi. $(A)$ : rễ $C 5$ hai bên bình thường (mũi tên xanh). (B): nhổ rễ $C 7$ bên trái kèm thoát vị màng não tủy ngang mức

Độ nhạy, độ đặc hiệu, độ chính xác, giá trị dự đoán dương tính và giá trị dự đoán âm tính đối với chẩn đoán tổn thương đứt rễ thần kinh sau hạch trong nghiên cứu của chúng tôi lần lượt là $78,7 \%$, 89,8\%,84,7\%,86,7\% và 83,2\%. Độ nhạy, độ đặc hiệu, độ chính xác, giá trị dự đoán dương tính và giá trị dự đoán âm tính đối với chẩn đoán u thần kinh lần lượt là 92,6\%, 84,3\%, 87,2\%, 75,6\% và $95,6 \%$. U thần kinh là rối loạn tái tạo cấu trúc sợi trục ở đoạn gần của dây thần kinh sau chấn thương, tương đương với tổn thương độ III hoặc IV theo phân độ Sunderland..$^{3,6,9}$ Khi có đứt của dây thần kinh, tương ứng với khi các lớp bao nội thần kinh hoặc bao bó thần kinh bị tổn thương, tại vị trí điểm đứt các cấu trúc axon có sự tái tạo thành dạng khối gồm những tế bào Schwan, nguyên bào sợi và các sợi trục với myelin. ${ }^{10}$ Theo tác giả Medina, $\mathrm{CHT}$ có độ nhạy và độ đặc hiệu cao trong chẩn đoán u thần kinh với tỷ lệ lần lượt là $93 \%$ và $100 \% .{ }^{8}$ Ngoài u thần kinh thì mô sẹo cũng là một tổn thương làm dày lên của rễ thần kinh sau chấn thương, đây là tổn thương của cấu trúc xung quanh các thành phần của ĐRTKCT, không ảnh hưởng tới bao nội thần kinh và bao bó thần kinh, các cấu trúc này co kéo và ngăn cản các đầu thần kinh tái tạo gặp nhau. $U$ thần kinh và mô sẹo đôi khi khó chẩn đoán phân biệt trên các phương tiện chẩn đoán hình ảnh. 6,9 Theo tác giả Lihong Zhang ${ }^{7}$, độ nhạy, độ đặc hiệu và độ chính xác trong chẩn đoán tổn thương sau hạch lần lượt là 91,3\%,60\% và 85,71\%.

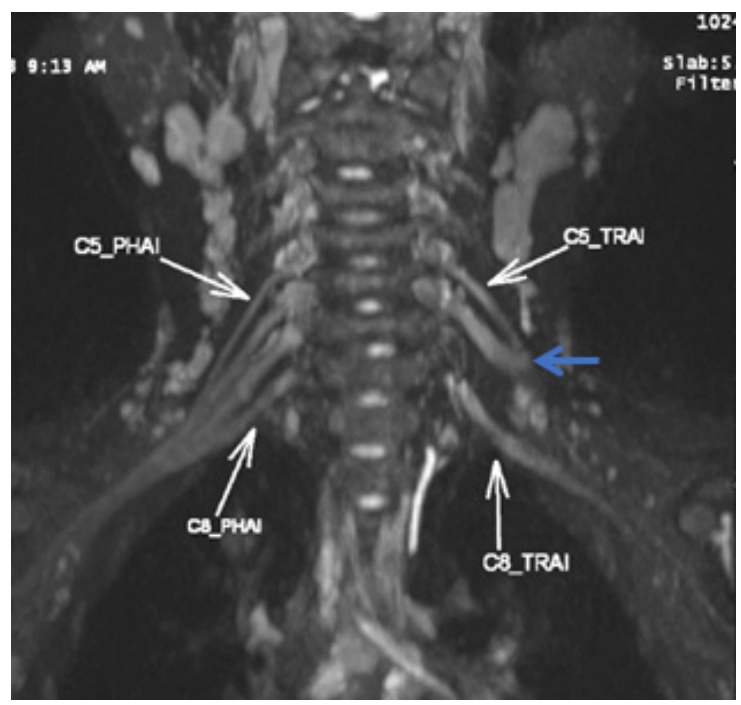

Hình 2. Coronal STIR ở trẻ nữ 7 tuổi có tổn thương ĐRTKCT trái : phù nề rễ $\mathrm{C} 5$ trái (tăng kích thước và tăng tín hiệu so với bên đối diện); đứt rễ $\mathrm{C} 6$ bên trái kèm neuroma (mũi tên xanh); đứt rễ $C 7$ với đầu ngoại vi co rút lại cạnh vị trí đứt của rễ $\mathbf{C 6}$

Theo kinh nghiệm của chúng tôi, việc kết hợp giữa triệu chứng trên lâm sàng và điện cơ rất hữu ích trong việc định hướng và khẳng định sự phù hợp về vị trí tổn thương trên hình ảnh $\mathrm{CHT}$. Hạn chế của điện cơ trong khảo sát trước mổ là không có khả năng phát hiện ra nhổ rễ trong bối cảnh của một tổn thương sau hạch nghiêm 
trọng cùng tồn tại, tuy nhiên trong các trường hợp bệnh nhân có biểu hiện trên lâm sàng mà không có tổn thương sau hạch thì cần xem xét kĩ tổn thương nhổ các rễ con trước hạch, đặc biệt khi các rễ này nhỏ, không có dấu hiệu giả thoát vị màng não tủy có thể gây âm tính giả trên hình ảnh CHT.

Việc chỉ định phẫu thuật dựa trên sự cân nhắc giữa các yếu tố về mặt lâm sàng, điện cơ và chẩn đoán hình ảnh. Yếu tố về thời gian và sự hồi phục trên lâm sàng: theo tác giả Gilbert và trường đại học Toronto, nếu sau 3 tháng mà chưa có dấu hiệu về sự tự phục hồi thì cần tiên lượng phẫu thuật, nếu có dấu hiệu hồi phục thì phục hồi chức năng và đánh giá lại lúc trẻ 6 - 9 tháng còn đối với hướng dẫn của trường đại học Michigan lấy mốc 6 tháng. Các yếu tố tiên lượng khả năng phục hồi nếu được can thiệp sớm bao gồm: phân loại Nakaras, sự hiện diện của gãy xương đòn, hội chứng Horner trên lâm sàng, sự hiện diện giả thoát vị màng não tủy trên hình ảnh, cân nặng trẻ và các biện pháp hỗ trợ trong khi sinh. ${ }^{11,12}$ Chẩn đoán vị trí tổn thương trước hạch và sau hạch có ý nghĩa quan trọng trong việc đưa ra quyết định điều trị và lựa chọn phương pháp phẫu thuật. Phẫu thuật chấn thương ĐRTKCT bao gồm sửa chữa, cắt bỏ hay bóc tách dây thần kinh, cắt bỏ u thần kinh, ghép thần kinh, chuyển vị dây thần kinh và chuyển cơ. Tổn thương trước hạch, chủ yếu là nhổ rễ thần kinh - mất sự liên kết của rễ với hệ thần kinh trung ương, việc nối thần kinh là không có ý nghĩa, vì vậy phẫu thuật được lựa chọn là chuyển vị thần kinh, trong đó thần kinh ngoài vị trí thoát ra được cắt bỏ và nối tăng cường vào vị trí nhánh tận của đám rối. ${ }^{2}$ Đối với tổn thương sau hạch, liên kết của rễ với hệ thần kinh trung ương còn được bảo tồn, việc ghép nối thần kinh vi phẫu sau khi cắt bỏ mô sẹo và neuroma có tác dụng. 2,13,14 Phẫu thuật tạo hình gồm chuyển gân và hoặc tạo hình xương góp phần cải thiện độ linh hoạt và hoạt động chủ động của khớp vai. Đánh giá hồi phục sau phẫu thuật được thực hiện dựa trên mức độ phục hồi vận động theo 2 thang điểm là Mallet và $A B C$ loops. Theo tác giả Phan Đức Minh Mẫn nghiên cứu về sự hồi phục sau phẫu thuật tổn thương ĐRTKCT có 37 trong số 39 bệnh nhân hồi phục sau phẫu thuật, 2 bệnh nhân không thấy dấu hiệu hồi phục sau 1 năm. Nhóm bị tổn thương 2 rễ thần kinh cho kết quả hồi phục tốt hơn nhóm liệt hoàn toàn, tỷ lệ hồi phục nhóm tổn thương $\mathrm{C} 5$, $\mathrm{C} 6$ và $\mathrm{C} 5, \mathrm{C} 6$ và $\mathrm{C} 7$ là $64 \% .{ }^{15}$ Theo tác giả Gilbert và Tassin, biểu hiện cơ nhị đầu co trong 3 tháng đầu là dấu hiệu chỉ điểm cho quá trình hồi phục, sau đó mức độ hồi phục xảy ra với tam đầu, cơ delta là một dấu hiệu tiên lượng rất tốt. ${ }^{16}$

\section{KÉT LUẬN}

CHT 3T là phương tiện chẩn đoán hình ảnh không xâm lấn, có độ phân giải và giá trị cao trong đánh giá tổn thương ĐRTKCT sản khoa ở trẻ em, cho phép phát hiện, phân độ và phân biệt vị trí tổn thương trước hạch hay sau hạch, từ đó giúp bác sĩ lâm sàng và các phẫu thuật viên đưa ra kế hoạch điều trị, phương án lựa chọn phương pháp phẫu thuật phù hợp, kịp thời nhằm đem lại hiệu quả phục hồi cao nhất, tránh để lại di chứng cho trẻ.

\section{TÀI LIẸU THAM KHẢO}

1. Lindqvist $P G$, Erichs $K$, Molnar $C$, Gudmundsson S, Dahlin LB. Characteristics and outcome of brachial plexus birth palsy in neonates. Acta Paediatr Oslo Nor 1992. 2012;101(6):579 - 582. doi:10.1111/j.1651 2227.2012.02620.

2. Somashekar D, Yang LJS, Ibrahim M, Parmar HA. High - resolution MRI evaluation of neonatal brachial plexus palsy: A promising alternative to traditional CT myelography. AJNR Am J Neuroradiol. 2014;35(6)1209 - 13. doi: https://doi.org/10.3174/ajnr.a3820.

3. Torres C, Mailley K, O'Donovan 
$R$ del C. MRI of the Brachial Plexus: Modified Imaging Technique Leading to a Better Characterization of Its Anatomy and Pathology. Neuroradiol J. 2013;26(6):699. doi:10.1177/197140091302600614.

4. Upadhyaya V, Upadhyaya DN, Kumar A, Pandey AK, Gujral R, Singh AK. Magnetic resonance neurography of the brachial plexus. Indian J Plast Surg Off Publ Assoc Plast Surg India. 2015;48(2):129 - 137. doi:10.4103/0970 0358.163045 .

5. Tagliafico A, Succio G, Emanuele Neumaier $C$, et al. MR imaging of the brachial plexus: comparison between 1.5 - $\mathrm{T}$ and 3 - T MR imaging: preliminary experience. Skeletal Radiol. 2011;40(6):717 - 724. doi:10.1007/ s00256 - 010 - 1050 - x.

6. Gunes A, Bulut E, Uzumcugil A, Oguz KK. Brachial Plexus Ultrasound and MRI in Children with Brachial Plexus Birth Injury. AJNR Am J Neuroradiol. 2018;39(9):1745 - 50. doi: https://doi.org/10.3174/ajnr.a5749.

7. Zhang L, Xiao T, Yu Q, Li Y, Shen F, Li W. Clinical Value and Diagnostic Accuracy of 3.0T Multi - Parameter Magnetic Resonance Imaging in Traumatic Brachial Plexus Injury. Med Sci Monit. 2018;24:7199 - 205. doi:10.12659/ MSM.907019.

8. Medina LS, Yaylali I, Zurakowski D, Ruiz J, Altman NR, Grossman JAI. Diagnostic performance of MRI and MR myelography in infants with a brachial plexus birth injury. Pediatr Radiol. 2006;36(12):1295 - 9. doi:10.1007/ s00247 - 006 - 0321 - 0.

9. Sureka J, Cherian RA, Alexander M, Thomas BP. MRI of brachial plexopathies. Clin Radiol. 2009;64(2):208 - 18. doi:10.1016/j. crad.2008.08.011.

10. Abbott R, Abbott M, Alzate J, Lefton
D. Magnetic resonance imaging of obstetrical brachial plexus injuries. Childs Nerv Syst ChNS Off J Int Soc Pediatr Neurosurg. 2004;20(10):720 - 725. doi:10.1007/s00381 $004-1003-6$.

11. Smith BW, Daunter AK, Yang LJS, Wilson TJ. An Update on the Management of Neonatal Brachial Plexus Palsy - Replacing Old Paradigms: A Review. JAMA Pediatr. 2018;172(6):585 - 91. doi: https://doi. org/10.1001/jamapediatrics.2018.0124.

12. Waters PM. Update on management of pediatric brachial plexus palsy. $J$ Pediatr Orthop B. 2005;14(4):233 - 44. doi: https://doi. org/10.1097/01202412 - 200507000 - 00001.

13. Singer $A D$, Meals $C$, Kesner $V$, et al. The Multidisciplinary Approach to the Diagnosis and Management of Nonobstetric Traumatic Brachial Plexus Injuries. Am J Roentgenol. 2018;211(6):1319 - 1331. doi:10.2214/ AJR.18.19887.

14. Smith BW, Chang KWC, Parmar HA, Ibrahim M, Yang LJS. MRI evaluation of nerve root avulsion in neonatal brachial plexus palsy: understanding the presence of isolated dorsal/ventral rootlet disruption. J Neurosurg Pediatr. 2021;27(5):589 - 593. doi:10.3171/2020.9.PEDS20326.

15. Phan Đức Minh Mẫn, Đặng Khải Minh, Võ Chiêu Tài, et al. Bước đầu đánh giá điều trị liệt đám rối thần kinh cánh tay trẻ em do sanh tại Việt Nam. Y học TP Hồ Chí Minh, tập 17 Phụ bản số 3.

16. Gilbert A, Tassin JL. Obstetrical palsy: a clinical, pathologic, and surgical review. In: Terzis JK (Ed.) Microreconstruction of nerve injuries. Philadelphia, WB Saunders, 1987: 529-53. 


\section{Summary \\ DIAGNOSTIC ACCURACY OF 3 TESLA MAGNETIC RESONANCE IMAGING FOR CHILDREN OBSTETRIC BRACHIAL PLEXUS INJURY}

The objective of the study was to evaluate the diagnostic value of $3 T$ MRI in diagnosing obstetric brachial plexus injury lesions in children. This was a prospective study, conducted on 47 patients who had clinical and electromyography manifestations of obstetric brachial plexus injury. All of the patients went through 3T MRI before surgery in Vinmec Hospital (Hanoi, Vietnam) from 09/2016 to 03/2020 and surgically treated (at Viet Duc and National Pediatric hospitals, Hanoi, Vietnam). The pre- and post-ganglionic injuries on MRI was correlated with intraoperative findings. Sensitivity, specificity, accuracy, positive predictive value and negative predictive value for diagnosis of pre-nodal lesions were $89.7 \%, 93.2 \%, 92.3 \%, 81.3 \%$ and $96.5 \%$ respectively; diagnosis of postganglionic nerve root rupture were $78.7 \%, 89.8 \%, 84.7 \%, 86.7 \%$ and $83.2 \%$ respectively; diagnosis of nerve root neuroma were $92.6 \%, 84.3 \%, 87.2 \%, 75.6 \%$ and $95.6 \%$ respectively. We concluded that $3 \mathrm{~T} \mathrm{MRI}$ is a non-invasive diagnostic method, with high accuracy in diagnosing obstetric brachial plexus injury lesions in children, both for pre- and post-ganglionic injuries.

Keywords: Obstetric brachial plexus injury, 3T MRI, Erb's palsy. 